\title{
LAUDAGE, Johannes, LEIVERKUS, Yvonne, Rittertum und höfische Kultur der Stauferzeit
}

\section{Géraldine Damon}

\section{OpenEdition}

\section{Journals}

Édition électronique

URL : http://journals.openedition.org/ifha/569

DOI : 10.4000/ifha.569

ISSN : 2198-8943

Éditeur

IFRA - Institut franco-allemand (sciences historiques et sociales)

Référence électronique

Géraldine Damon, «LAUDAGE, Johannes, LEIVERKUS, Yvonne, Rittertum und höfische Kultur der Stauferzeit », Revue de l'IFHA [En ligne], Date de recension, mis en ligne le 01 janvier 2007, consulté le 22 septembre 2020. URL : http://journals.openedition.org/ifha/569; DOI : https://doi.org/10.4000/ ifha.569

Ce document a été généré automatiquement le 22 septembre 2020.

(C)IFHA 


\title{
LAUDAGE, Johannes, LEIVERKUS, Yvonne, Rittertum und höfische Kultur der Stauferzeit
}

\author{
Géraldine Damon
}

Les actes de ce colloque réuni en juin 2005 à l'université Heinrich-Heine de Düsseldorf rassemblent treize contributions se penchant sur la dialectique à l'œuvre entre chevalerie et culture courtoise dans l'Empire des Staufen. Ils s'ouvrent sur la synthèse érudite de J. LAUDAGE, attentif à la terminologie, qui rappelle les conditions d'émergence de la militia, réalité juridique et sociale multiple au confluent des sphères de la domination et du service, mais aussi groupe d'élite que rapprochent une même fonction militaire et une même culture née à la cour. Dans une démonstration non dénuée d'intérêt mais quelque peu en marge du propos, K. GÖRICH s'arrête ensuite sur le concept d'honor imperii qu'invoquent les Staufen au titre de raccourci programmatique pour légitimer leur politique en Italie et motiver l'adhésion des princes germaniques.

Deux études de cas proposent une plongée au cœur de la cour. J. LAUDAGE esquisse celle de Frédéric Barberousse en y distinguant la curia minor, cercle quotidien formé d'un petit groupe de confiance, de la curia major, rassemblement ostentatoire du groupe dominant. La comparaison avec d'autres cours occidentales fait apparaître la souplesse de cette organisation encore embryonnaire, fondée sur le consensus des princes quand la cour capétienne entend domestiquer la noblesse, où l'absence de comptabilité systématique comme à la cour anglaise ou d'institutions pérennes comme à la cour de Cologne fragilise la position matérielle de l'empereur mais lui confère en retour un champ de manœuvre plus large et le rôle central de garant de la cohésion et de l'intégration nobiliaires. En écho, Th. KÖLZER dresse un tableau attendu de la cour royale de Sicile au temps de Frédéric II, modèle bureaucratique adossé au triple héritage grec, arabe et normand, où l'empereur favorise l'ascension des juristes, restreint le cercle des hommes de confiance et encourage par son mécénat l'éclat de ce 
centre intellectuel et culturel de premier plan marqué par le cosmopolitisme et la translatio.

Sont ensuite abordés les soubassements économiques de cette culture chevaleresque et courtoise des XIIe et XIIIe s. qui correspond à l'expansion démographique et économique de l'Occident. W. RÖSENER envisage tour à tour l'itinérance des cours souveraines destinée à assurer leur approvisionnement dans une économie en voie de monétarisation, la corrélation entre l'éclat culturel d'une cour et le développement économique à travers plusieurs exemples régionaux, et enfin les conséquences sociales de l'augmentation du coût de la chevalerie au XIIIe s. J. ULLRICH déduit quant à lui du Tafelgüterverzeichnis du règne de Frédéric Ier, qui détaille pour quatre régions les services dus lorsqu'y réside la cour impériale, l'importance de la suite de l'empereur ; la démarche, quantitative et peu distanciée, peine néanmoins à convaincre.

La culture et les représentations constituent le dernier volet de cette réflexion collective. A. PLASSMANN choisit de partir du regard des clercs extérieurs au milieu curial ou étrangers, tel Gautier Map vantant la supériorité morale de la cour du roi de France sur celle d'Henri II, pour évoquer la culture courtoise en France aux XIe et XIIe s. et son rayonnement. B. Haupt entend montrer à partir de l'Erec d'Hartmann von Aue que les idéaux chevaleresques sont issus de la cour et de la diffusion du modèle princier, et non de la militia christi forgée par l'idéologie de la croisade. L'exposé d'Y. LEVERKUS qui se penche sur l'évolution de l'armement et la mise en scène de normes et d'idéaux chevaleresques à partir de représentations iconographiques, tombe malheureusement dans l'anecdote, faute de perspective générale. Revenant sur le " procès de civilisation » mis en avant par N. Elias, J. U. KEUPP souligne la diffusion des normes de contrôle social au sein de la cour des Staufen sous l'influence des dames et des clercs, jusqu'à déplorer d'ailleurs au XIIIe s. l'effeminatio de la chevalerie d'Empire. G. LUBICH interroge pour sa part le concept médiéval de Tugendadel en s'arrêtant sur le lieu social où naît cet idéal et sur le réagencement du rapport entre la naissance et le mérite dans le spectre des valeurs nobiliaires avec l'ascension des ministériaux (ou comment l'on passe de la promotion des vertus de la noblesse, Adelstudgenden, à une noblesse de la vertu, Tugendadel, à partir des Carolingiens et de la réforme monastique). Enfin, J. LAUDAGE, décidément très prolifique, dépeint Frédéric Barberousse comme un homme de transition, y compris sur le plan de la guerre où il incarne durant la campagne de Milan en 1158 le " rationalisme de l'honneur ", combinaison entre l'honneur chevaleresque individuel et la rationalité du chef de guerre stratège.

Chargé de conclure, Th. ZOTZ ébauche la prochaine étape qui sera de replacer le temps des Staufen dans le temps long de l'histoire germanique pour dégager les ruptures et les continuités ainsi que les tensions affleurant sous l'image harmonieuse de la culture chevaleresque et courtoise née du rapprochement du miles et du clericus.

Si les ambitions comparatistes et pluridisciplinaires supposées renouveler ce champ de recherche déjà bien exploré ne sont pas toujours tenues, le résultat offre au final une large vue du sujet tout en faisant le point sur l'historiographie de manière tout à fait bienvenue. L'ensemble aurait néanmoins gagné à suivre explicitement un cheminement thématique qu'il incombe ici au lecteur de reconstituer.

Géraldine DAMON (Université de Poitiers) 